\title{
Angiolymphoid Hyperplasia with Eosinophilia Treated with Isotretinoin
}

\author{
Sunil N. Petkar ${ }^{1}$, Venkatesh Giri², Pranit Farande ${ }^{3}$, Jigar Patel ${ }^{4}$, Asha Kushwaha ${ }^{5}$ \\ ${ }^{1}$ Department of Dermatology and Venereology, Terna Medical College, Nerul, Mumbai, Maharashtra, India. \\ ${ }^{2}$ Department of Paediatrics, Terna Medical College, Nerul, Mumbai, Maharashtra, India. ${ }^{3}$ Department of Dermatology \\ and Venereology, Terna Medical College, Nerul, Mumbai, Maharashtra, India. ${ }^{4}$ Department of Dermatology and \\ Venereology, Terna Medical College, Nerul, Mumbai, Maharashtra, India. ${ }^{5}$ Department of Dermatology and \\ Venereology, Terna Medical College, Nerul, Mumbai, Maharashtra, India.
}

\section{INTRODUCTION}

Angiolymphoid Hyperplasia with Eosinophilia (ALHE) is an uncommon benign clinical entity characterized by the presence of a variable number of papules, plaques or nodules of the dermis and subcutaneous tissues.[1] ALHE shows a predilection for the head and neck area. ${ }^{[2]}$ ALHE is a benign neoplasm of the vascular endothelium. ALHE is also called as epithelioid hemangioma, a term that better describes the most distinguishing feature of this entity -the abnormal proliferation of endothelial cells. [3] The etiology of ALHE is obscure; however, it has been reported to occur in pregnancy and also following trauma in some cases.[2]

Angiolymphoid hyperplasia with eosinophilia (ALHE) is a rare and idiopathic vascular disorder. It is characterized by red to brown papules and nodules, typically localized on the head and neck, particularly around the ear as singular or multiple lesions. Although ALHE is a benign disease, lesions are often persistent and difficult to eradicate. Young to middle age women are more commonly affected. The histological examination corresponds to a florid vascular proliferation with atypical endothelial cells surrounded by a lymphocytic and eosinophilic infiltrate. We describe a young male with solitary nodular lesion over the left side of neck below left ear with scar mimicking scrofuloderma; the histological examination was consistent with ALHE.

ALHE was first described by Wells and Whimster ${ }^{[4]}$ who defined it as a late stage of Kimura disease. Since then there has been a lot of controversy about these two conditions. Nowadays it is widely accepted to be different entities. ALHE is a rare, benign, vasoproliferative disease of unknown origin. It is characterized by intradermal or subcutaneous single or multiple reddish-brown papules or nodules, mainly on the head and neck, especially around the ears.[5,6] Less often lesions of ALHE have been described in the mouth, on the trunk, extremities, vulva and penis.

Affects mostly young to middle-aged females of any race, may complain about itching, tenderness or pulsation of the lesions. They do not have lymphadenopathy or peripheral eosinophilia in comparison with Kimura disease.[5,6,7]

The pathogenetic mechanism of ALHE is unknown. In some cases, there is a preceding trauma, a recently published article described ALHE after an ear piercing. ${ }^{[8]}$ Some reporters suggest it is related to infection and high estrogen status. Nevertheless, there seems to be consensus that ALHE is a reactive rather than a neoplastic process. $[6,9,10]$

\author{
Corresponding Author: \\ Dr. Pranit Farande, \\ Shankarsheela Complex, Shop No. 1, \\ Sector-8, Airoli, Navi Mumbai-400708, \\ Maharashtra, India. \\ E-mail:fpranit@gmail.com
}

DOI: $10.14260 /$ jemds/2019/870

Financial or Other Competing Interests: None.

How to Cite This Article:

Petkar SN, Giri V, Farande $P$, et al. Angiolymphoid hyperplasia with eosinophilia treated with isotretinoin. J. Evolution Med. Dent. Sci. 2019;8(52):40204022, DOI: $10.14260 /$ jemds/2019/870

Submission 13-06-2019,

Peer Review 26-10-2019,

Acceptance 31-10-2019,

Published 30-12-2019.

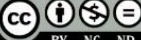


PRESENTATION OF CASE

A twenty years old Muslim male attended our out-patient department with complaint of nodular swelling over left side of neck below the ear since 3 months. It was treated with antibiotics with no improvement. It was removed surgically 2 months back followed by recurrence in few days. There was no history of fever or weight loss, no history of preceding trauma. The general examination was not significant. There was no evidence of any lymphadenopathy. On cutaneous examination a single non-tender nodule was present over apex of left sided posterior triangle of neck. The surface was ulcerated with yellowish crust. A scar was seen over surrounding skin. On palpation the nodule was firm in consistency with restricted mobility. (Figure-1, 2, 3). No other significant skin lesions seen.

\section{CLINICAL DIAGNOSIS}

Scrofuloderma

\section{DIFFERENTIAL DIAGNOSIS}

Angiolymphoid Hyperplasia with Eosinophilia

\section{PATHOLOGICAL DISCUSSION}

$\mathrm{CBC}$ and other routine blood and urine investigations were within normal limit. Chest X-ray showed no abnormality. Histopathology of biopsy showed increased number of thick walled and dilated blood vessels (capillaries and venules) involving the whole of reticular dermis. Around these vessels and at time in their walls was an infiltrate of lymphocytes and several eosinophils. The lining of these vessels showed thick endothelial cells that projected into the lamina giving a 'hob nail' appearance. The epidermis was missing and the surface was covered by necrotic inflammatory cells and plasma. These findings were suggestive of Angiolymphoid Hyperplasia with Eosinophilia. (Figure-5, 6, 7)

\section{DISCUSSION OF MANAGEMENT}

Patient was started on Cap Isotretinoin $20 \mathrm{mg}$ daily. Within 20 days the lesions resolved completely. Patient was continued on Isotretinoin for 3 months. Patient tolerated the medicine well without any major side effects. He was followed up for next three months after stopping isotretinoin with no recurrence (Figure-3).

The treatment of ALHE is challenging because of the high recurrence rate, however surgical excision remains the treatment of choice. Many other therapeutic options for ALHE have been discussed in the literature including radiotherapy, indomethacin, laser therapy $\left(\mathrm{CO}_{2}\right.$, argon, copper vapour, pulsed dye, Nd: YAG), photodynamic therapy, corticosteroids, cryotherapy, electrodessication, pentoxiphylline, intralesional steroid, intralesional bleomycin, Interferon-a, thalidomide, oral isotretinoin[11] and acitretin. Unfortunately, ALHE tends to recur. Because it is a benign disease and malignant change never has been reported so far, interventions should not be too aggressive.
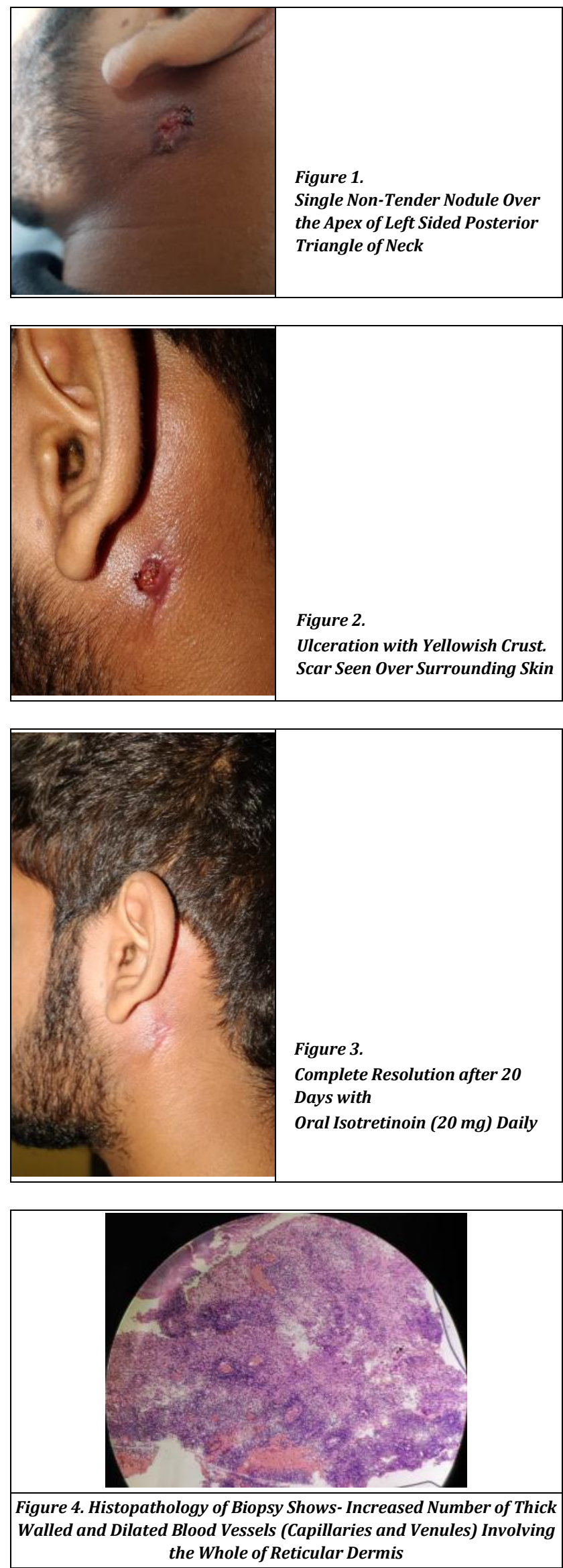

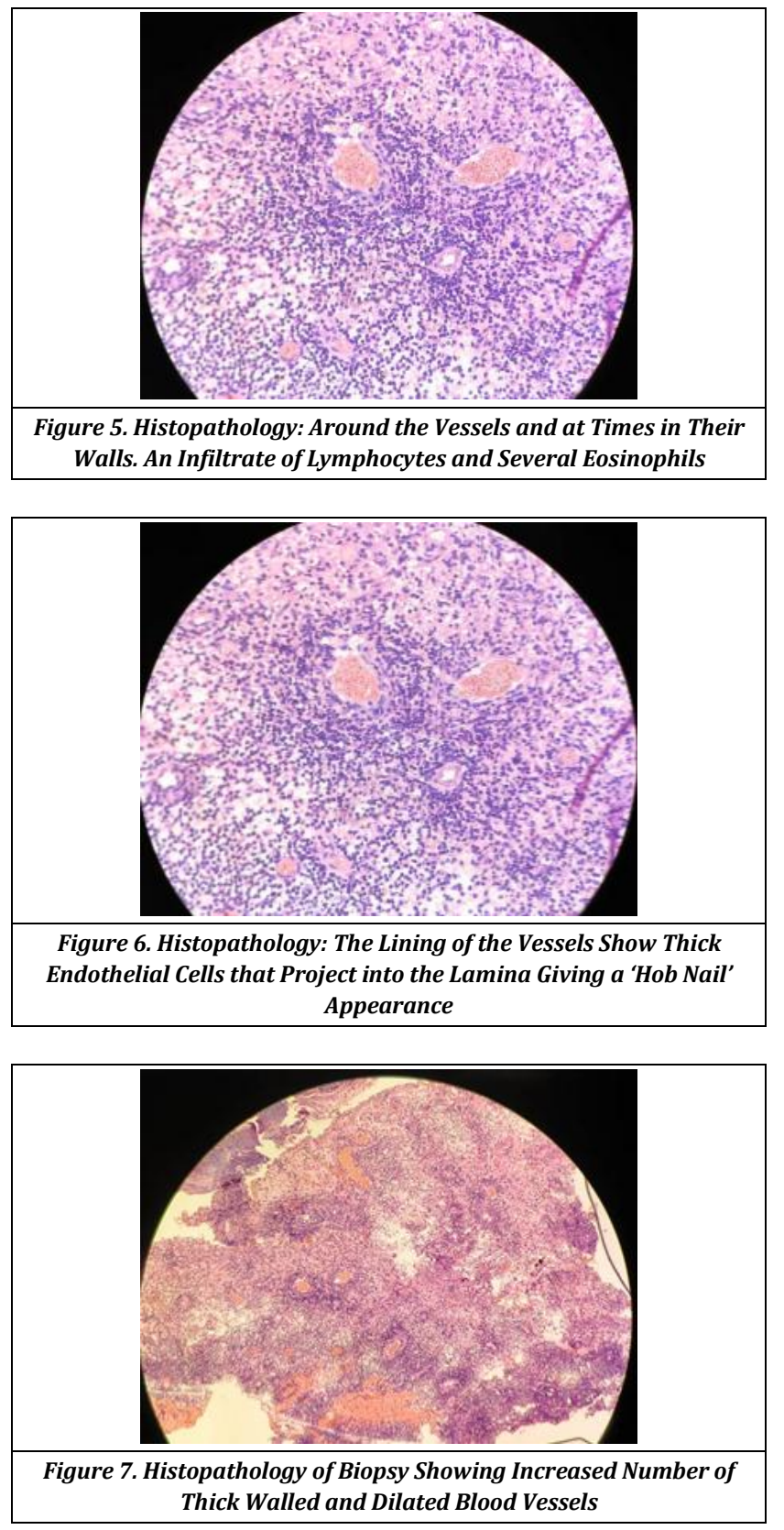

FINAL DIAGNOSIS

Angiolymphoid Hyperplasia with Eosinophilia (ALHE)

\section{REFERENCES}

[1] Wolff K, Goldsmith L, Katz S, et al. Fitzpatricks Textbook of Dermatology in General medicine. $7^{\text {th }}$ edn. Elsevier Publication 2008: p. 313-5.

[2] Gonzalez-Cuyar LF, Tavora F, Zhao XF, et al. Angiolymphoid hyperplasia with eosinophilia developing in a patient with history of peripheral T-cell lymphoma: evidence for multicentric T-cell lymphoproliferative process. Diagn Pathol 2008;3:22.

[3] Weiss SW, Enzinger FM. Epithelioid hemangioendothelioma: a vascular tumor often mistaken for a carcinoma. Cancer 1982;50(5):970-81.

[4] Wells GC, Whimster IW. Subcutaneous angiolymphoid hyperplasia with eosinophilia. $\mathrm{Br} \mathrm{J}$ Dermatol 1969;81(1):1-14.

[5] Olsen TG, Helwig EB. Angiolymphoid hyperplasia with eosinophilia. A clinicopathologic study of 116 patients. J Am Acad Dermatol 1985;12(5 Pt 1):781-96.

[6] Requena L, Sangueza OP. Cutaneous vascular proliferations. Part II. Hyperplasias and benign neoplasms. J Am Acad Dermatology 1997;37(6):887919.

[7] Chun SI, Ji HG. Kimura's disease and angiolymphoid hyperplasia with eosinophilia: clinical and histopathologic differences. J Am Acad Dermatol 1992;27(6 Pt 1):954-8.

[8] Okman JS, Bhatti TR, Jackson OA, et al. Angiolymphoid hyperplasia with eosinophilia: a previously unreported complication of ear piercing. Pediatr Dermatol 2014;31(6):738-41.

[9] Chong WS, Thomas A, Goh CL. Kimura's disease and angiolymphoid hyperplasia with eosinophilia: two disease entities in the same patient: case report and review of the literature. Int J Dermatol 2006;45(2):139. 45.

[10] San Nicoló M, Mayr D, Berghaus A. Angiolymphoid hyperplasia with eosinophilia of the external ear: case report and review of the literature. Eur Arch Otorhinolaryngol 2013;270(10):2775-7.

[11] Carlesimo M, Mari E, Tammaro A, et al. Angiolymphoid hyperplasia with eosinophilia treated with isotretinoin. Eur J Dermatol 2007;17(6):554-5. 